\title{
In the Wnt-er of life: Wnt signalling in melanoma and ageing
}

\author{
Amanpreet Kaur ${ }^{1,2}$, Marie R Webster ${ }^{1}$ and Ashani T Weeraratna*,1 \\ ${ }^{1}$ Tumor Microenvironment and Metastasis Program, The Wistar Institute, Philadelphia, PA, USA and ${ }^{2}$ University of the Sciences, \\ Philadelphia, PA, USA
}

\begin{abstract}
Although the clinical landscape of melanoma is improving rapidly, metastatic melanoma remains a deadly disease. Age remains one of the greatest risk factors for melanoma, and patients older than 55 have a much poorer prognosis than younger individuals, even when the data are controlled for grade and stage. The reasons for this disparity have not been fully uncovered, but there is some recent evidence that Wnt signalling may have a role. Wnt signalling is known to have roles both in cancer progression as well as in organismal ageing. In melanoma, the interplay of Wnt signalling pathways is complex, with different members of the Wnt family guiding different aspects of invasion and proliferation. Here, we will briefly review the current literature addressing the roles of different Wnt pathways in melanoma pathogenesis, provide an overview of Wnt signalling during ageing, and discuss the intersection between melanoma and ageing in terms of Wnt signalling.
\end{abstract}

\section{AGE IS A PROGNOSTIC FACTOR FOR MELANOMA}

As human lifespan increases, there is a growing concern over the availability of treatments to manage the increasing incidence of cancer in aged individuals. Recently, comparison of melanoma incidence and mortality rates across different age groups indicated a worse prognosis with increasing age (Macdonald et al, 2011). Aged populations (those $>70$ years at the time of diagnosis) tend to have deeper primary melanomas as well as a higher number of metastasis than younger populations. Consequently, these aged patients are generally identified in the $\mathrm{T} 3$ or $\mathrm{T} 4$ stages of melanomas, where the primary lesion depth is $>2 \mathrm{~mm}$ (T3) and $>4 \mathrm{~mm}$ (T4). Aged patients also have a greater chance of recurrence ( $14.9 \%$ vs $3.4-6 \%, P<0.001$, within 5 years of surgery) and higher mortality from the disease $(29.8 \%$ vs $12.3 \%, P<0.001$, 5 years after surgery; Macdonald et al, 2011). These data suggest it is critical to identify the molecular mechanisms for these variations in disease outcome.

Factors such as changes in adaptive immunity, chronic inflammation and the accumulation of genetic damage over time have all been proposed as potential age-related factors in the ageinduced increase in cancer incidence and progression (Wolters and Schumacher, 2013; Zanussi et al, 2013). However, other data suggest that secreted factors in the aged microenvironment may also contribute to the age-induced progression of cancer. For example, it has long been proposed that the ageing stroma contributes to cancer progression, based on the studies using senescence as an artificial model of ageing (Campisi, 2013; Campisi and Robert, 2014). Senescent dermal fibroblasts have been shown to support the growth and invasion of melanoma cells in co-culture models (Kim et al, 2013), suggesting that naturally aged fibroblasts may have similar roles. This studies provide further insight into the age-related progression observed in melanoma and other cancers, and suggest that the microenvironment may have a dominant role in age-induced melanoma progression. It has been recently shown that Yumm1.7 melanoma cells, derived from the Braf $^{\mathrm{m} 1 \mathrm{Mmcm}}$ Ptent $^{\text {m1Hwu }} \operatorname{Tg}$ (Tyr-cre/ERT2)13Bos/BosJ mouse model of melanoma, when injected into mice aged over a year, were highly metastatic and did not respond effectively to therapy, as compared with the same cells in 8-week-old animals (Kaur et al, 2016). Patient data also indicate that patients over the age of 65 respond poorly to targeted therapy, and this appears to be driven largely by changes in Wnt signalling, triggered by fibroblast-secreted Wnt inhibitors, such as sFRP2. In fact, the Wnt signalling pathway has a significant role during organismal ageing and may ultimately affect melanoma outcome. In this review, we will describe the role of Wnt signalling in melanoma and its potential contribution to agerelated increases in melanoma progression.

*Correspondence: Dr AT Weeraratna; E-mail: aweeraratna@wistar.org

Received 31 May 2016; revised 10 September 2016; accepted 15 September 2016; published online 20 October 2016 


\section{THE WNT SIGNALLING PATHWAYS}

Wnt signalling comprises a family of proteins that are involved in cell proliferation, differentiation, polarity and cell fate determination. Though the primary role of Wnts is in development, abnormal signalling through these pathways has been implicated in ageing and many human cancers. Wnts may signal via three distinct pathways; the canonical pathway, the $\mathrm{Ca}^{2+} / \mathrm{PKC}$ pathway and the planar cell polarity pathway. Wnt signalling is mediated by cellular receptors known as the frizzled family of receptors, which are G-protein-coupled receptors. In addition to Frizzleds, Wnt signalling also requires multiple co-receptors, such as ROR1 and ROR2, LRP5/6 and Ryk. To add further complexity, a variety of secreted Wnt-related proteins such as sFRP2, WISP1, WIF1 and others, also interact to guide Wnt signalling. The best-known Wnt signalling pathway involves the intermediate signalling molecule $\beta$-catenin and is termed the canonical pathway. Non-canonical Wnt signalling includes both the $\mathrm{Ca}^{2}+$ PKC pathway and the planar cell polarity pathway mediated via Jnk signalling. In melanoma, the non-canonical pathway most commonly observed is that of the $\mathrm{Ca}^{2+} / \mathrm{PKC}$ pathway, usually mediated by Wnt5A. Extensive reviews of the basic transduction mechanisms of both the canonical and non-canonical Wnt pathways are available, thus we will not focus on those in this minireview, but refer the reader to the following reviews (Chien et al, 2009; O'Connell and Weeraratna, 2009).

Wnt signalling in melanoma initiation. The importance of Wnt in developing skin can be realised through the developmental stages of neural crest cells, which migrate and give rise to melanocytes. Wnt signalling guides both the migration of the cells from the neural crest and signals to determine cell fate. The fate of neural crest cells is dependent on the microphthalmia transcription factor (MITF) that is regulated by $\beta$-catenin, such that cells with high levels of MITF will differentiate into melanocytes, whereas cells with low MITF give rise to neurons, cartilage, glial cells and others (Mort et al, 2015). Differentiated melanocytes are responsible for the production of melanin, which is secreted and transferred to keratinocytes, resulting in skin pigmentation. An important stimulator of this process is the melanocortin-stimulating hormone $(\alpha-\mathrm{MSH})$, which results in the activation of the cAMPK/PKA signalling pathway. When PKA is activated, it can phosphorylate serine 9 on GSK $3 \beta$, thus inhibiting its activity (Fang et al, 2000). In addition, it has been shown that PKA can phosphorylate the serine 675 residue of $\beta$-catenin directly, and that this phosphorylation event prevents the ubiquitination and subsequent degradation of $\beta$-catenin (Hino et al, 2005). Therefore, $\alpha-\mathrm{MSH}$, via PKA activation, is thought to result in the accumulation and activation of $\beta$-catenin signalling (Tachibana, $2000) . \beta$-Catenin activation in melanoma seems to occur largely via increases in signalling such as this and less commonly via mutation. Once activated, $\beta$-catenin is critical for the bypassing of melanocyte senescence, which can ultimately result in the transformation of melanocytes (Delmas et al, 2007). This is perpetuated by $\beta$-catenin-mediated activation of the POU domain transcription factor Brn2 (Goodall et al, 2004).

After activation, Brn2 can have a complex role in the regulation of MITF. It has been found that Brn2 directly binds to and represses MITF. In one study, the authors showed that co-staining of melanoma samples for Brn2 and MITF defined a distinct demarcation between MITF-positive and Brn2-positive cells (Goodall et al, 2008). Introducing Brn2 into MITF-positive cells repressed MITF activity. However, depletion of Brn2 has also been shown to decrease MITF levels, suggesting that in some cases, Brn2 promotes MITF activity. This discrepancy may be owing to the presence of oncogenic BRAF as the use of deletion mutants demonstrated that Brn2 bound to the MITF promoter, and drove its activity, in the presence of oncogenic BRAF (Wellbrock et al, 2008). Knockdown of either Brn 2 or BRAF inhibited MITF transcriptional activity. Therefore, the difference in whether Brn2 is able to transcribe or repress MITF may be dependent on cellular context. For example, in the presence of oncogenic BRAF, Brn2 may drive MITF-mediated proliferation, but in its absence, it may repress MITF and promote invasion. Post-translational modifications such as phosphorylation also regulate the function of Brn2 and its effects on cellular proliferation, as shown by Berlin et al (2012), and MITF is known to function as a 'rheostat' where, depending on the levels of its expression and activity, MITF signalling can result in both inhibition and promotion of melanoma growth (Goding, 2011). Very low levels of MITF or absence of MITF results in a population of completely arrested, potentially senescent cells (Vachtenheim and Ondrusova, 2015). Low levels of MITF result in the emergence of a slow-cycling, stemlike, highly invasive population of cells marked by high expression of p27 and the cell cycle regulator, Dial (Carreira et al, 2006). Increasing MITF above this threshold pushes cells towards a highly proliferative phenotype, and finally, increasing MITF even further can drive cells into terminal differentiation (Vachtenheim and Ondrusova, 2015). MITF is therefore thought to be a master regulator of the phenomenon of 'phenotype switching', where it is hypothesised that cells switch back and forth between proliferative and invasive states. This governs how cells leave a tumour and then establish distant metastases (Hoek and Goding, 2010). MITF expression can be regulated by canonical Wnt signalling as described above and non-canonical Wnt signalling as described below, and thus Wnt signalling can differentially affect each phase of the 'rheostat'. Although the MITF rheostat can also be controlled by a number of other factors including TGF $\beta$, hypoxia, inflammatory cytokines, and so on, for the purpose of this review, we will focus on Wnt signalling.

Wnt signalling in invasion. As melanoma cells switch to an invasive phenotype, they activate non-canonical Wnt signalling, specifically via Wnt5A. Wnt5A signals via frizzled (Fzd) receptors Fzd2 and 5, along with the orphan tyrosine kinase receptor ROR2, to activate PKC and stimulate the release of intracellular calcium (Webster et al, 2015a). This results in multiple downstream outcomes such as the induction of calpain-mediated cleavage of filamin leading to increased motility, and the upregulation of vimentin and snail, resulting in a transition to an invasive, mesenchymal phenotype (reviewed in O'Connell and Weeraratna, 2009). Activation of Wnt5A also inhibits MITF expression, via the activation of STAT3. STAT3 inhibits the binding of MITF and PAX3 to the promoter regions of melanocyte differentiation antigens such as MART1, GP100 and DCT (Kamaraju et al, 2002). Wnt5A-mediated activation of STAT3 reduces MITF levels and ultimately downregulates the expression of melanocyte differentiation antigens (Dissanayake et al, 2008). All of these outcomes act in consort to promote a metastatic phenotype.

In addition, Wnt5A signals to promote the degradation of $\beta$-catenin, via a GSK $3 \beta$-independent pathway that involves the ubiquitin ligase SIAH2 (Topol et al, 2003). These data suggest that $\beta$-catenin loss is critical for invasion and were supported by additional studies that implicated $\beta$-catenin loss in melanoma metastasis (Chien et al, 2009; Arozarena et al, 2011). However, the role of $\beta$-catenin in melanoma metastasis is highly controversial. Although Arozarena et al (2011) have shown that the loss of $\beta$-catenin promotes the invasion of human melanoma cells, studies in mice contradict this observation. The stabilisation of the $\beta$-catenin allele in the B6.Cg-Braf ${ }^{\mathrm{tm} 1 \mathrm{Mmcm}}$ Ptent ${ }^{\mathrm{m} 1 \mathrm{Hwu}} \mathrm{Tg}(\mathrm{Tyr}-\mathrm{cre} /$ ERT2)13Bos/BosJ melanoma mouse model increases the metastatic progression of melanoma in these mice (Damsky et al, 2011). In a more recent study, Gallagher et al (2013) showed that although 
$\beta$-catenin did not promote cell motility, it did promote metastatic outgrowth. This may have to do with the requirement for cells to switch from an invasive phenotype and re-enter proliferation once they have reached the distant metastatic site. It is possible that microenvironmental influences at the metastatic niche govern the switch to the proliferative state. It will be critical to understand how dichotomous Wnt signalling guides different phases of metastatic progression, especially in a temporal context.

Wnt signalling in therapy resistance of melanoma. There have been multiple improvements in the clinical landscape of melanoma over the last decade. Most significantly, these include therapy targeted against mutant BRAF and its downstream signalling (BRAF inhibitors), and immunotherapy. However, resistance, or in the case of immunotherapy, lack of response, continues to be a problem. In addition to metastasis, Wnt signalling may guide response to multiple forms of therapy in melanoma cells. Wnt inhibitors such as DKK3 are upregulated in dermal fibroblasts co-cultured with melanoma cells treated with BRAF inhibitors, and promote therapy resistance, potentially via $\beta$-catenin inactivation (Seip et al, 2016). In support of this, data show that treating dermal fibroblasts with another Wnt inhibitor such as recombinant sFRP2 inhibits their expression of $\beta$-catenin, and leads to resistance to BRAF inhibitors in vitro and in vivo. Inhibiting sFRP2 with monoclonal antibodies reconstitutes $\beta$-catenin expression and resensitises tumours to BRAF inhibitors (Kaur et al, 2016).

Although increased $\beta$-catenin has been shown to sensitise melanoma cells to the BRAF inhibitor, vemurafenib (Biechele et al, 2012), non-canonical Wnt signalling has been shown to contribute to increased resistance to this drug (O'Connell et al, 2013; Anastas et al, 2014), highlighting the opposing roles of the different Wnt pathways in resistance as well as invasion and growth. Wnt5A promotes resistance to vemurafenib partly by the SIAH2-mediated degradation of $\beta$-catenin and partly by driving cells into a senescent-like, drug-resistant state (pseudosenescence). In this pseudosenescent state, Wnt5A-high cells retain all the hallmarks of senescence while still maintaining a highly invasive phenotype, and the capability to form metastatic outgrowth in the lung (Webster et al, 2015b). Wnt5A cells initiate pseudosenescence whether treated with irradiation, targeted therapy or doxorubicin, suggesting that this is likely a non-specific stress response that allows melanoma cells to survive damage. It is intriguing to note that although Wnt5A, which makes melanoma cells resistant to BRAF inhibitors, drives cells into senescence, and $\beta$-catenin, which makes melanoma cells sensitive to drug, drives cells to bypass senescence (Delmas et al, 2007; Conde-Perez et al, 2015). This suggests that senescence may be a mechanism that melanoma cells co-opt to escape cytotoxic drugs. Therefore, designing therapies that promote senescence as a means of controlling disease could potentially do more harm than good, and caution should be taken when investigating such therapies.

In the immunotherapy setting, some controversy exists regarding the role of Wnt signalling in response to therapy. For many years, mutant-stabilised $\beta$-catenin was considered an antigen, against which antigen-specific T-cell therapy could be directed (Wang and Rosenberg, 1996). Furthermore, increased $\beta$-catenin increases MITF, and MITF is then able to transcribe melanocytic antigens such as MART1 and gp100, which are known to trigger the infiltration of cytotoxic $\mathrm{T}$ cells into the tumour microenvironment. In support of this, as previously mentioned, increases in Wnt5A were shown to shut off this pathway, inhibiting MITF and abrogating MART1 expression. This resulted in a decrease in the activation of MART1-recognising T cells (Dissanayake et al, 2008). Although these data are consistent with each other, recent studies examining the effects of checkpoint inhibitors in melanoma have highlighted some inconsistencies. In a recent study, Spranger et al (2015) showed that, in contrast to that early work from the Wang and Rosenberg (1996), mutant-stabilised $\beta$-catenin caused exclusion of $\mathrm{T}$ cells from melanoma tumours and reduced the efficacy of checkpoint inhibitors. More recently, Wnt5A was identified as a marker of non-response in patients undergoing checkpoint inhibitor therapy (Hugo et al, 2016). This supports earlier data that demonstrated that melanoma-derived Wnt5A increases the expression of indoleamine 2,3-dioxygenase-1 (IDO) in dendritic cells (Holtzhausen et al, 2015). Indoleamine 2,3-dioxygenase-1 is the ratelimiting enzyme in the tryptophan catabolism pathway, and acts to deplete tryptophan in $\mathrm{T}$ cells, inhibiting their ability to function normally, thus acting as an immune checkpoint (Prendergast et al, 2014). Wnt5A, therefore, may implement its immunosuppressive abilities via multiple mechanisms. The role of $\beta$-catenin in increasing or suppressing the immune microenvironment remains less clear.

MICROENVIRONMENTAL EFFECTS OF WNT SIGNALLING IN MELANOMA: AGEING

The stromal microenvironment of melanoma is composed of immune cells, extracellular matrix and fibroblasts, as well as keratinocytes and endothelial cells. $\beta$-Catenin is highly expressed in normal fibroblasts and is important in maintaining normal fibroblast function (Zhou et al, 2016). $\beta$-Catenin ablation in fibroblasts slows their proliferation rate, but mimics the activity of cancer-associated fibroblasts. Cancer-associated fibroblasts are also known to signal via the Wnt pathways, and secrete Wnt/planar cell polarity pathway molecules, such as Frizzled, Vangl, Dvl and Pk via exosomes (Luga and Wrana, 2013). However, normal dermal fibroblasts also secrete Wnt inhibitors, such as WISP1 (WNT1inducible signalling pathway protein 1) and Dickkopf family member proteins, suggesting that the Wnt pathway is tightly regulated in dermal fibroblasts. For example, secretion of WISP1 is regulated by Notch1 in dermal fibroblasts and prevents early melanoma progression in mice (Shao et al, 2011). Whereas DKK1 inhibits $\beta$-catenin-mediated signalling in normal dermal fibroblasts, as do other DKK family member proteins, particularly DKK3, which acts on melanoma cells (Akhmetshina et al, 2012).

Wnt pathways, which have a role in development, also regulate skin ageing, and the skin makes up the stromal microenvironment with which primary melanoma cells interact during the initial stages of tumourigenesis. The balance of Wnt signalling molecules and Wnt inhibitors changes during ageing, and may affect not only tumour progression, but also resistance to therapy. Changes in multiple Wnt signalling pathways occur during ageing and these results have been summarised in Table 1 . Below, we will discuss a few key contributors to age-related changes in Wnt signalling in melanoma.

sFRP2 and oxidative stress. It has recently been shown that the Wnt inhibitor sFRP2 is secreted by aged dermal fibroblasts, and inhibits $\beta$-catenin signalling in melanoma cells. This sets up a signalling cascade that results in the inhibition of the base-excision repair protein APE1, a known target of MITF (Liu et al, 2009), and the accumulation of oxidative stress and DNA damage, leading to genomic instability (summarised in Figure 1). In addition to tumour cells, Wnt-mediated oxidative stress changes can also be observed in cancer-associated stromal fibroblasts as well as stromal fibroblasts from aged individuals (Comito et al, 2012; Kaur et al, 2016). Dermal fibroblasts undergoing oxidative stress have also been shown to recruit melanoma cells from the primary lesion to produce new satellite metastases. The increase in oxidative stress in aged fibroblasts can be reversed by using antioxidants such as $N$-acetyl cysteine (NAC; Comito et al, 2012; Kaur et al, 2016). Antioxidant therapies remain controversial, as studies have shown that although NAC is effective in reducing ROS-mediated DNA damage in primary melanoma tumours, it increased the number 
and burden of lymph node metastases in young mice (aged 3 weeks; Piskounova et al, 2015). However, oxidative stress in young mice is known to be lower than in the mice $>52$ weeks, thus highlighting the importance of understanding the role of age in determining the outcome of antioxidant intervention therapies (Kaur et al, 2016).

Klotho, an inhibitor of Wnt signalling. Klotho is a single-pass transmembrane protein, with an extracellular domain that can be cleaved, generating a secreted form of klotho that circulates in the blood (Yokoyama et al, 2012). In humans, klotho is secreted into the serum until about 35 years of age, and then lost rapidly thereafter (Takumida et al, 2009). Klotho is often called the 'antiageing hormone' and loss of klotho was observed to decrease lifespan in mice, whereas overexpression of klotho prolonged lifespan. Klotho also prevents oxidative stress in klotho-overexpressing transgenic mice as well as in cultured cell lines (Yamamoto et al, 2005). The antioxidant effects of klotho were mediated via transcriptional activation of FOXO proteins, which activate mitochondrial superoxide dismutase, SOD2, thereby promoting survival of irreplaceable cells that may otherwise die during ageing (Yamamoto et al, 2005). In addition, klotho has been shown to suppress p21 and cellular senescence (Xie et al, 2013).

In a klotho knockout mouse model, increased canonical Wnt signalling was observed, suggesting that klotho inhibits Wnt signalling (Liu et al, 2007). This appears to occur via regulation of Wnt binding to the cell surface, as the secreted form of klotho has sialidase activity allowing it to modify glycans on the cell surface (Kuro-o, 2009; O'Connell et al, 2009). It has been previously shown that $\mathrm{Wnt5 \textrm {A }}$ requires the heparan sulphate proteoglycan syndecan to enhance its signalling. In the presence of klotho, the sialic acid residues on syndecan are cleaved, and Wnt5A is released from the cell surface, such that it can no longer signal as effectively to mediate metastasis. In addition, klotho signals to inhibit calpain activity, maintaining the integrity of filaminA and inhibiting the motility of melanoma cells. In accordance with these observations in vitro, it was also found that melanoma cells lose klotho expression as they become more metastatic, and reintroducing klotho can inhibit metastasis (Camilli et al, 2011). As klotho is expressed by fibroblasts, it will be of interest to examine the agerelated effects of stromal sources of klotho on the malignant progression of melanoma cells.

Telomere length and $\boldsymbol{\beta}$-catenin signalling. Telomere length attrition can contribute to premature ageing and the precancerous state by promoting chromosomal instability (Hoffmeyer et al, 2012). To survive, cancer cells upregulate telomerase expression, increasing telomere length and promoting survival. Telomere length is maintained by telomerase, a reverse transcriptase enzyme that carries an RNA template used to elongate telomere ends. Mutations in the promoter region of functional subunit of telomerase, TERT, occur in the vast majority of human melanoma cell lines $(\sim 70 \%)$ and also in cutaneous melanoma in patients ( $\sim 43 \%$ ). The frequency of the mutation varies among the different subtypes of melanoma (Horn et al, 2013). These mutations tend to be activating, and generate new ETS-binding motifs (Huang et al,

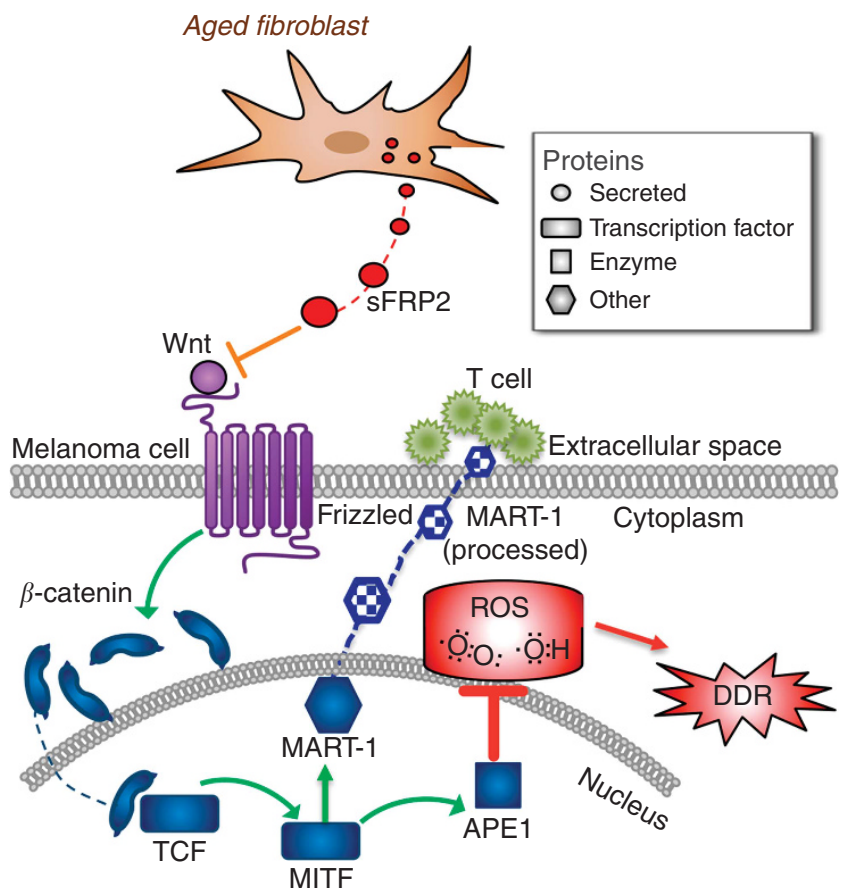

Figure 1. Schematic representation of Wnt signalling in the aged microenvironment of melanoma. In melanoma cells, $\beta$-catenin signals to increase microphthalmia transcription factor (MITF), which in turn can signal to activate the base-excision repair endonuclease, APE1. This enzyme acts to protect the cells from ROS-induced DNA damage. MITF also signals to increase transcription of melanoma-associated antigens such as MART1, which is processed, presented on the surface of the cell and acts to increase the influx of cytotoxic T cells. During ageing, aged fibroblasts secrete sFRP2, which inhibits canonical Wnt signalling such as Wnt1 and Wnt3a. Inhibiting canonical Wnts inhibit $\beta$-catenin, resulting in an ablation of this protective signalling cascade. This allows the cells to accumulate DNA damage and become more genomically unstable. This also leads to less antigen presentation, and therefore, a decreased susceptibility to cytotoxic $T$ cells.

Table 1. Changes in Wnt pathway proteins with normal skin ageing

\begin{tabular}{|c|c|c|}
\hline Source & Proteins/other factors & Reference \\
\hline \multicolumn{3}{|c|}{ Increased in aged population } \\
\hline $\begin{array}{l}\text { Female skin } \\
\text { Male skin } \\
\text { Female and } \\
\text { male skin } \\
\text { In vitro }\end{array}$ & $\begin{array}{l}\text { sFRP2, WISP2, ROR1, FZD1, IL4, TNF, NEU1, MMP1, MMP3, } \\
\text { POT1, SRSF9, CALM1, THBS1, miR-29c } \\
\text { TYR, NKD1, FZD8, LRP8, CXCL12, IL4R, IFNGR1, CCL5, CCL2 } \\
\text { WIF1, AXIN2, FZD7, CORIN, IL8 } \\
\text { MMP1, MMP3, CCR2, CCL3, CCND1, SOD3, IL6 }\end{array}$ & $\begin{array}{l}\text { Makrantonaki et al (2012); Waldera-Lupa et al (2014); Waldera Lupa et al } \\
\text { (2015); Kalfalah et al (2015); Kaur et al (2016) } \\
\text { Makrantonaki et al (2012); Breitenbach et al (2015); Waldera Lupa et al (2015) } \\
\text { Makrantonaki et al (2012); Waldera Lupa et al (2015) } \\
\text { Dudonne et al (2011); Elewa et al (2015) }\end{array}$ \\
\hline \multicolumn{3}{|c|}{ Increased in young population } \\
\hline $\begin{array}{l}\text { Female skin } \\
\text { Male skin } \\
\text { Female and } \\
\text { male skin } \\
\text { In vitro }\end{array}$ & $\begin{array}{l}\text { LRAP, TERT, TP53, TGFB1, MEN1, PLK1, DDX3X, miR-181a, miR- } \\
\text { 409-3p, FLNC } \\
\text { CAMK1G, NFATC2, IL22RA1, IL1R2 } \\
\text { SIRT6 } \\
\text { E2F4, KLF10, GLRX, PPAR- } \alpha \text { TL4R, CTNNB1 }\end{array}$ & $\begin{array}{l}\text { Makrantonaki et al (2012); Waldera-Lupa et al (2014); Kalfalah et al (2015); } \\
\text { Waldera Lupa et al (2015) } \\
\text { Makrantonaki et al (2012); Breitenbach et al (2015) } \\
\text { Makrantonaki et al (2012) } \\
\text { Dudonne et al (2011); Elewa et al (2015); Kaur et al (2016) }\end{array}$ \\
\hline
\end{tabular}


2013). TERT-promoter mutations were associated with poorer overall survival in melanoma patients (80 vs 291 months, $P<0.006$; Griewank et al, 2014).

TERT regulates Wnt signalling by two main mechanisms. First, TERT acts in a complex with BRG1 (a SWI-/SNF-related ATPdependent chromatin-remodelling factor), directly binding to the $\beta$-catenin promoter region and activating its transcriptional activity (Park et al, 2009). In the absence of BRG1, TERT is unable to activate $\beta$-catenin and its downstream signalling proteins (Park et al, 2009). Next, TERT also binds directly to $\beta$-catenin target sites, specifically to the TBE-containing promoter fragments of the c-myc and Cyclin D1 genes. This regulation appears to be reciprocal, as $\beta$-catenin can contribute to telomere stability. TERT is highly expressed in adult stem cells with stabilised $\beta$-catenin (Heidenreich et al, 2014). Upregulation of $\beta$-catenin increases levels of TRF2, a subunit of the shelterin complex that protects telomere ends, and allows for protection of telomeres in both cancer and normal cells (Diala et al, 2013). Loss of nuclear $\beta$ catenin increases telomere damage by triggering formation of telomere dysfunction-induced foci, (telomere foci co-localising with 53BP1), decreasing cell viability and causing the cells to enter senescence (Diala et al, 2013). It is unclear whether this senescence is terminal, or whether it represents a pseudosenescent state, which allows these cells to survive the onslaught of therapy. This association of DNA damage with the loss of $\beta$-catenin is also seen in melanoma cells exposed to an aged microenvironment (Kaur et al, 2016). The interaction of TERT with $\beta$-catenin provides another nodal point where ageing and Wnt signalling may intersect to govern melanoma progression.

\section{CONCLUSION}

Wnt signalling has critical roles in the development and ageing of organisms, and Wnts are thus very highly conserved. The role of these proteins in the growth and lineage specification of normal cells is co-opted by tumour cells to increase malignancy, and as such, Wnt proteins can have multiple and diverse roles in tumour development and progression. Perhaps one of the most fascinating things to observe in recent studies is the ever-burgeoning variety of cellular processes in which Wnt signalling has a role in melanoma, as highlighted in this review-growth, metastasis, resistance to targeted therapy, immune-modulation and, most recently, ageingrelated changes in the disease. One of the ways in which ageing and melanoma intersect in terms of Wnt signalling is via the release of sFRP2 from aged fibroblasts, which signals to shut off $\beta$-catenin in the melanoma cells. This triggers a host of downstream changes that ultimately lead to altered response to ROS, and the initiation of DNA damage (Figure 1). There may be a host of other Wnt-related mechanisms that also change during ageing and trigger similar pro-tumourigenic effects. This recently added complexity of microenvironmental Wnt-related proteins that affect the melanoma cells and are altered during ageing, makes the understanding of the spatio-temporal roles of the different players in this pathway critical for better design of effective therapy in melanoma.

\section{CONFLICT OF INTEREST}

The authors declare no conflict of interest.

\section{REFERENCES}

Akhmetshina A, Palumbo K, Dees C, Bergmann C, Venalis P, Zerr P, Horn A, Kireva T, Beyer C, Zwerina J, Schneider H, Sadowski A, Riener MO,
Macdougald OA, Distler O, Schett G, Distler JH (2012) Activation of canonical Wnt signalling is required for TGF-beta-mediated fibrosis. Nat Commun 3: 735.

Anastas JN, Kulikauskas RM, Tamir T, Rizos H, Long GV, Von Euw EM, Yang PT, Chen HW, Haydu L, Toroni RA, Lucero OM, Chien AJ, Moon RT (2014) WNT5A enhances resistance of melanoma cells to targeted BRAF inhibitors. J Clin Invest 124: 2877-2890.

Arozarena I, Bischof H, Gilby D, Belloni B, Dummer R, Wellbrock C (2011) In melanoma, beta-catenin is a suppressor of invasion. Oncogene $\mathbf{3 0}$ : 4531-4543.

Berlin I, Denat L, Steunou AL, Puig I, Champeval D, Colombo S, Roberts K, Bonvin E, Bourgeois Y, Davidson I, Delmas V, Nieto L, Goding CR, Larue L (2012) Phosphorylation of BRN2 modulates its interaction with the Pax3 promoter to control melanocyte migration and proliferation. Mol Cell Biol 32: 1237-1247.

Biechele TL, Kulikauskas RM, Toroni RA, Lucero OM, Swift RD, James RG, Robin NC, Dawson DW, Moon RT, Chien AJ (2012) Wnt/betacatenin signaling and AXIN1 regulate apoptosis triggered by inhibition of the mutant kinase BRAFV600E in human melanoma. Sci Signal 5: ra3.

Breitenbach JS, Rinnerthaler M, Trost A, Weber M, Klausegger A, Gruber C, Bruckner D, Reitsamer HA, Bauer JW, Breitenbach M (2015) Transcriptome and ultrastructural changes in dystrophic epidermolysis bullosa resemble skin aging. Aging 7: 389-411.

Camilli TC, Xu M, O'Connell MP, Chien B, Frank BP, Subaran S, Indig FE, Morin PJ, Hewitt SM, Weeraratna AT (2011) Loss of Klotho during melanoma progression leads to increased filamin cleavage, increased Wnt5A expression, and enhanced melanoma cell motility. Pigment Cell Melanoma Res 24: 175-186.

Campisi J (2013) Aging, cellular senescence, and cancer. Annu Rev Physiol 75: 685-705.

Campisi J, Robert L (2014) Cell senescence: role in aging and age-related diseases. Interdiscip Top Gerontol 39: 45-61.

Carreira S, Goodall J, Denat L, Rodriguez M, Nuciforo P, Hoek KS, Testori A, Larue L, Goding CR (2006) Mitf regulation of Dial controls melanoma proliferation and invasiveness. Genes Dev 20: 3426-3439.

Chien AJ, Conrad WH, Moon RT (2009) A Wnt survival guide: from flies to human disease. J Invest Dermatol 129: 1614-1627.

Comito G, Giannoni E, Di Gennaro P, Segura CP, Gerlini G, Chiarugi P (2012) Stromal fibroblasts synergize with hypoxic oxidative stress to enhance melanoma aggressiveness. Cancer Lett 324: 31-41.

Conde-Perez A, Gros G, Longvert C, Pedersen M, Petit V, Aktary Z, Viros A, Gesbert F, Delmas V, Rambow F, Bastian BC, Campbell AD, Colombo S, Puig I, Bellacosa A, Sansom O, Marais R, Van Kempen LC, Larue L (2015) A caveolin-dependent and PI3K/AKT-independent role of PTEN in betacatenin transcriptional activity. Nat Commun 6: 8093.

Damsky WE, Curley DP, Santhanakrishnan M, Rosenbaum LE, Platt JT, Gould Rothberg BE, Taketo MM, Dankort D, Rimm DL, Mcmahon M, Bosenberg M (2011) Beta-catenin signaling controls metastasis in Brafactivated Pten-deficient melanomas. Cancer Cell 20: 741-754.

Delmas V, Beermann F, Martinozzi S, Carreira S, Ackermann J, Kumasaka M, Denat L, Goodall J, Luciani F, Viros A, Demirkan N, Bastian BC, Goding CR, Larue L (2007) Beta-catenin induces immortalization of melanocytes by suppressing p16INK4a expression and cooperates with N-Ras in melanoma development. Genes Dev 21: 2923-2935.

Diala I, Wagner N, Magdinier F, Shkreli M, Sirakov M, Bauwens S, Schluth-Bolard C, Simonet T, Renault VM, Ye J, Djerbi A, Pineau P, Choi J, Artandi S, Dejean A, Plateroti M, Gilson E (2013) Telomere protection and TRF2 expression are enhanced by the canonical Wnt signalling pathway. EMBO Rep 14: 356-363.

Dissanayake SK, Olkhanud PB, O'Connell MP, Carter A, French AD, Camilli TC, Emeche CD, Hewitt KJ, Rosenthal DT, Leotlela PD, Wade MS, Yang SW, Brant L, Nickoloff BJ, Messina JL, Biragyn A, Hoek KS, Taub DD, Longo DL, Sondak VK, Hewitt SM, Weeraratna AT (2008) Wnt5A regulates expression of tumor-associated antigens in melanoma via changes in signal transducers and activators of transcription 3 phosphorylation. Cancer Res 68: 10205-10214.

Dudonne S, Coutiere P, Woillez M, Merillon JM, Vitrac X (2011) DNA macroarray study of skin aging-related genes expression modulation by antioxidant plant extracts on a replicative senescence model of human dermal fibroblasts. Phytother Res 25: 686-693.

Elewa RM, Abdallah MA, Zouboulis CC (2015) Age-associated skin changes in innate immunity markers reflect a complex interaction 
between aging mechanisms in the sebaceous gland. J Dermatol 42: 467-476.

Fang X, Yu SX, Lu Y, Bast JR. RC, Woodgett JR, Mills GB (2000) Phosphorylation and inactivation of glycogen synthase kinase 3 by protein kinase A. Proc Natl Acad Sci USA 97: 11960-11965.

Gallagher SJ, Rambow F, Kumasaka M, Champeval D, Bellacosa A, Delmas V, Larue L (2013) Beta-catenin inhibits melanocyte migration but induces melanoma metastasis. Oncogene 32: 2230-2238.

Goding CR (2011) Commentary. A picture of Mitf in melanoma immortality. Oncogene 30: 2304-2306.

Goodall J, Carreira S, Denat L, Kobi D, Davidson I, Nuciforo P, Sturm RA, Larue L, Goding CR (2008) Brn-2 represses microphthalmia-associated transcription factor expression and marks a distinct subpopulation of microphthalmia-associated transcription factor-negative melanoma cells. Cancer Res 68: 7788-7794.

Goodall J, Martinozzi S, Dexter TJ, Champeval D, Carreira S, Larue L, Goding CR (2004) Brn-2 expression controls melanoma proliferation and is directly regulated by beta-catenin. Mol Cell Biol 24: 2915-2922.

Griewank KG, Murali R, Puig-Butille JA, Schilling B, Livingstone E, Potrony M, Carrera C, Schimming T, Moller I, Schwamborn M, Sucker A, Hillen U, Badenas C, Malvehy J, Zimmer L, Scherag A, Puig S, Schadendorf D (2014) TERT promoter mutation status as an independent prognostic factor in cutaneous melanoma. J Natl Cancer Inst 106: dju246.

Heidenreich B, Nagore E, Rachakonda PS, Garcia-Casado Z, Requena C, Traves V, Becker J, Soufir N, Hemminki K, Kumar R (2014) Telomerase reverse transcriptase promoter mutations in primary cutaneous melanoma. Nat Commun 5: 3401.

Hino S, Tanji C, Nakayama KI, Kikuchi A (2005) Phosphorylation of betacatenin by cyclic AMP-dependent protein kinase stabilizes beta-catenin through inhibition of its ubiquitination. Mol Cell Biol 25: 9063-9072.

Hoek KS, Goding CR (2010) Cancer stem cells versus phenotype-switching in melanoma. Pigment Cell Melanoma Res 23: 746-759.

Hoffmeyer K, Raggioli A, Rudloff S, Anton R, Hierholzer A, Del Valle I, Hein K, Vogt R, Kemler R (2012) Wnt/beta-catenin signaling regulates telomerase in stem cells and cancer cells. Science 336: 1549-1554.

Holtzhausen A, Zhao F, Evans KS, Tsutsui M, Orabona C, Tyler DS, Hanks BA (2015) Melanoma-derived Wnt5a promotes local dendritic-cell expression of IDO and immunotolerance: opportunities for pharmacologic enhancement of immunotherapy. Cancer Immunol Res 3: 1082-1095.

Horn S, Figl A, Rachakonda PS, Fischer C, Sucker A, Gast A, Kadel S, Moll I, Nagore E, Hemminki K, Schadendorf D, Kumar R (2013) TERT promoter mutations in familial and sporadic melanoma. Science 339: 959-961.

Huang FW, Hodis E, Xu MJ, Kryukov GV, Chin L, Garraway LA (2013) Highly recurrent TERT promoter mutations in human melanoma. Science 339: 957-959.

Hugo W, Zaretsky JM, Sun L, Song C, Moreno BH, Hu-Lieskovan S, Berent-Maoz B, Pang J, Chmielowski B, Cherry G, Seja E, Lomeli S, Kong X, Kelley MC, Sosman JA, Johnson DB, Ribas A, Lo RS (2016) Genomic and transcriptomic features of response to anti-PD-1 therapy in metastatic melanoma. Cell 165: 35-44.

Kalfalah F, Seggewiss S, Walter R, Tigges J, Moreno-Villanueva M, Burkle A, Ohse S, Busch H, Boerries M, Hildebrandt B, Royer-Pokora B, Boege F (2015) Structural chromosome abnormalities, increased DNA strand breaks and DNA strand break repair deficiency in dermal fibroblasts from old female human donors. Aging 7: 110-122.

Kamaraju AK, Bertolotto C, Chebath J, Revel M (2002) Pax3 down-regulation and shut-off of melanogenesis in melanoma B16/F10.9 by interleukin- 6 receptor signaling. J Biol Chem 277: 15132-15141.

Kaur A, Webster MR, Marchbank K, Behera R, Ndoye A, Kugel CH, Dang VM, Appleton J, O'Connell MP, Cheng P, Valiga AA, Morissette R, McDonnell NB, Ferrucci L, Kossenkov AV, Meeth K, Tang HY, Yin X, Wood WH, Lehrmann E, Becker KG, Flaherty KT, Frederick DT, Wargo JA, Cooper ZA, Tetzlaff MT, Hudgens C, Aird KM, Zhang R, Xu X, Liu Q, Bartlett E, Karakousis G, Eroglu Z, Lo RS, Chan M, Menzies AM, Long GV, Johnson DB, Sosman J, Schilling B, Schadendorf D, Speicher DW, Bosenberg M, Ribas A, Weeraratna AT (2016) sFRP2 in the aged microenvironment drives melanoma metastasis and therapy resistance. Nature 532: 250-254.

Kim E, Rebecca V, Fedorenko IV, Messina JL, Mathew R, Maria-Engler SS, Basanta D, Smalley KS, Anderson AR (2013) Senescent fibroblasts in melanoma initiation and progression: an integrated theoretical, experimental, and clinical approach. Cancer Res 73: 6874-6885.

Kuro-o M (2009) Klotho and aging. Biochim Biophys Acta 1790: 1049-1058.
Liu F, Fu Y, Meyskens Jr FL (2009) MiTF regulates cellular response to reactive oxygen species through transcriptional regulation of APE-1/Ref-1. J Invest Dermatol 129: 422-431.

Liu H, Fergusson MM, Castilho RM, Liu J, Cao L, Chen J, Malide D, Rovira II, Schimel D, Kuo CJ, Gutkind JS, Hwang PM, Finkel T (2007) Augmented Wnt signaling in a mammalian model of accelerated aging. Science 317: 803-806.

Luga V, Wrana JL (2013) Tumor-stroma interaction: revealing fibroblastsecreted exosomes as potent regulators of Wnt-planar cell polarity signaling in cancer metastasis. Cancer Res 73: 6843-6847.

Macdonald JB, Dueck AC, Gray RJ, Wasif N, Swanson DL, Sekulic A, Pockaj BA (2011) Malignant melanoma in the elderly: different regional disease and poorer prognosis. J Cancer 2: 538-543.

Makrantonaki E, Brink TC, Zampeli V, Elewa RM, Mlody B, Hossini AM, Hermes B, Krause U, Knolle J, Abdallah M, Adjaye J, Zouboulis CC (2012) Identification of biomarkers of human skin ageing in both genders. Wnt signalling - a label of skin ageing? PLoS One 7: e50393.

Mort RL, Jackson IJ, Patton EE (2015) The melanocyte lineage in development and disease. Development 142: 620-632.

O'Connell MP, Fiori JL, Kershner EK, Frank BP, Indig FE, Taub DD, Hoek KS, Weeraratna AT (2009) Heparan sulfate proteoglycan modulation of Wnt5A signal transduction in metastatic melanoma cells. J Biol Chem 284: 28704-28712.

O'Connell MP, Marchbank K, Webster MR, Valiga AA, Kaur A, Vultur A, Li L, Herlyn M, Villanueva J, Liu Q, Yin X, Widura S, Nelson J, Ruiz N, Camilli TC, Indig FE, Flaherty KT, Wargo JA, Frederick DT, Cooper ZA, Nair S, Amaravadi RK, Schuchter LM, Karakousis GC, Xu W, Xu X, Weeraratna AT (2013) Hypoxia induces phenotypic plasticity and therapy resistance in melanoma via the tyrosine kinase receptors ROR1 and ROR2. Cancer Discov 3: 1378-1393.

O'Connell MP, Weeraratna AT (2009) Hear the Wnt Ror: how melanoma cells adjust to changes in Wnt. Pigment Cell Melanoma Res 22: 724-739.

Park JI, Venteicher AS, Hong JY, Choi J, Jun S, Shkreli M, Chang W, Meng Z, Cheung P, Ji H, Mclaughlin M, Veenstra TD, Nusse R, Mccrea PD, Artandi SE (2009) Telomerase modulates Wnt signalling by association with target gene chromatin. Nature 460: 66-72.

Piskounova E, Agathocleous M, Murphy MM, Hu Z, Huddlestun SE, Zhao Z, Leitch AM, Johnson TM, Deberardinis RJ, Morrison SJ (2015) Oxidative stress inhibits distant metastasis by human melanoma cells. Nature 527: 186-191.

Prendergast GC, Smith C, Thomas S, Mandik-Nayak L, Laury-Kleintop L, Metz R, Muller AJ (2014) Indoleamine 2,3-dioxygenase pathways of pathogenic inflammation and immune escape in cancer. Cancer Immunol Immunother 63: 721-735.

Seip K, Fleten KG, Barkovskaya A, Nygaard V, Haugen MH, Engesaeter BO, Maelandsmo GM, Prasmickaite L (2016) Fibroblast-induced switching to the mesenchymal-like phenotype and PI3K/mTOR signaling protects melanoma cells from BRAF inhibitors. Oncotarget 7: 19997-20015.

Shao H, Cai L, Grichnik JM, Livingstone AS, Velazquez OC, Liu ZJ (2011) Activation of Notch1 signaling in stromal fibroblasts inhibits melanoma growth by upregulating WISP-1. Oncogene 30: 4316-4326.

Spranger S, Bao R, Gajewski TF (2015) Melanoma-intrinsic beta-catenin signalling prevents anti-tumour immunity. Nature 523: 231-235.

Tachibana M (2000) MITF: a stream flowing for pigment cells. Pigment Cell Res 13: 230-240.

Takumida M, Ishibashi T, Hamamoto T, Hirakawa K, Anniko M (2009) Agedependent changes in the expression of klotho protein, TRPV5 and TRPV6 in mouse inner ear. Acta Otolaryngol 129: 1340-1350.

Topol L, Jiang X, Choi H, Garrett-Beal L, Carolan PJ, Yang Y (2003) Wnt-5a inhibits the canonical Wnt pathway by promoting GSK-3-independent beta-catenin degradation. J Cell Biol 162: 899-908.

Vachtenheim J, Ondrusova L (2015) Microphthalmia-associated transcription factor expression levels in melanoma cells contribute to cell invasion and proliferation. Exp Dermatol 24: 481-484.

Waldera Lupa DM, Kalfalah F, Safferling K, Boukamp P, Poschmann G, Volpi E, Gotz-Rosch C, Bernerd F, Haag L, Huebenthal U, Fritsche E, Boege F, Grabe N, Tigges J, Stuhler K, Krutmann J (2015) Characterization of skin aging-associated secreted proteins (SAASP) produced by dermal fibroblasts isolated from intrinsically aged human skin. J Invest Dermatol 135: 1954-1968.

Waldera-Lupa DM, Kalfalah F, Florea AM, Sass S, Kruse F, Rieder V, Tigges J, Fritsche E, Krutmann J, Busch H, Boerries M, Meyer HE, Boege F, Theis F, Reifenberger G, Stuhler K (2014) Proteome-wide analysis reveals an 
age-associated cellular phenotype of in situ aged human fibroblasts. Aging 6: 856-878.

Wang RF, Rosenberg SA (1996) Human tumor antigens recognized by T lymphocytes: implications for cancer therapy. J Leukoc Biol 60: 296-309.

Webster MR, Kugel 3rd CH, Weeraratna AT (2015a) The Wnts of change: how Wnts regulate phenotype switching in melanoma. Biochim Biophys Acta 1856: 244-251.

Webster MR, Xu M, Kinzler KA, Kaur A, Appleton J, O'Connell MP, Marchbank K, Valiga A, Dang VM, Perego M, Zhang G, Slipicevic A, Keeney F, Lehrmann E, Wood 3rd W, Becker KG, Kossenkov AV, Frederick DT, Flaherty KT, Xu X, Herlyn M, Murphy ME, Weeraratna AT (2015b) Wnt5A promotes an adaptive, senescent-like stress response, while continuing to drive invasion in melanoma cells. Pigment Cell Melanoma Res 28: 184-195.

Wellbrock C, Rana S, Paterson H, Pickersgill H, Brummelkamp T, Marais R (2008) Oncogenic BRAF regulates melanoma proliferation through the lineage specific factor MITF. PLoS One 3: e2734.

Wolters S, Schumacher B (2013) Genome maintenance and transcription integrity in aging and disease. Front Genet 4: 19.
Xie B, Chen J, Liu B, Zhan J (2013) Klotho acts as a tumor suppressor in cancers. Pathol Oncol Res 19: 611-617.

Yamamoto M, Clark JD, Pastor JV, Gurnani P, Nandi A, Kurosu H, Miyoshi M, Ogawa Y, Castrillon DH, Rosenblatt KP, Kuro-O M (2005) Regulation of oxidative stress by the anti-aging hormone klotho. J Biol Chem 280: 38029-38034.

Yokoyama K, Imura A, Ohkido I, Maruyama Y, Yamazaki Y, Hasegawa H, Urae J, Sekino H, Nabeshima Y, Hosoya T (2012) Serum soluble alphaklotho in hemodialysis patients. Clin Nephrol 77: 347-351.

Zanussi S, Serraino D, Dolcetti R, Berretta M, De Paoli P (2013) Cancer, aging and immune reconstitution. Anticancer Agents Med Chem 13: 1310-1324.

Zhou L, Yang K, Wickett R, Zhang Y (2016) Dermal fibroblasts induce cell cycle arrest and block epithelial-mesenchymal transition to inhibit the early stage melanoma development. Cancer Med 5: 1566-1579.

(c) (1)(2) This work is licensed under the Creative Commons Ay Attribution-Non-Commercial-Share Alike 4.0 International License. To view a copy of this license, visit http:// creativecommons.org/licenses/by-nc-sa/4.0/ 